\title{
Post-hatching development of bovine embryos in vitro: the effects of tunnel preparation and gender
}

\author{
Grazieli Marinheiro Machado ${ }^{2,3}$, Ester Siqueira Caixeta ${ }^{2,3}$, Carolina Madeira Lucci ${ }^{3}$, Rodolfo Rumpf 2,3, \\ Maurício Machaim Franco ${ }^{2,3}$ and Margot Alves Nunes Dode $e^{1,3}$ \\ Laboratory of Animal Reproduction, Embrapa Genetic Resources and Biotechnology; and College of Agriculture and \\ Veterinary, University of Brasília, Campus Universitário Darcy Ribeiro, Asa Norte, Brasília, Brazil
}

Date submitted: 26.06.10. Date accepted: 27.10.10

\section{Summary}

\begin{abstract}
The objective of this study was to compare morphological characteristics, kinetics of development, and gene expression of male and female IVP embryos that were cultured until day (D)15 (fertilization = D0), using either phosphate-buffered saline (PBS) or Milli-Q water (MQW) to dilute the agarose gel used for tunnel construction. On D11, embryos $(n=286)$ were placed in agarose gel tunnels diluted in PBS and MQW. Embryos were evaluated for morphology, and embryo size was recorded on D11, D12.5, D14 and D15. Then, embryos were sexed and used for gene expression analyses (G6PD, GLUT1, GLUT3, PGK1, PLAC8, KRT8, HSF1 and IFNT). The percentage of elongated embryos at D15 was higher $(p<0.05)$ in the PBS $(54 \%)$ than in the MQW $(42 \%)$ gel. However, embryos produced in MQW were bigger $(p<0.05)$ and had a lower expression of GLUT1 $(p=0.08)$ than those cultured in PBS. There was a higher proportion of male than female embryos at D15 in both treatments, MQW (65\% vs. $35 \% ; p<0.05)$ and PBS $(67 \%$ vs. $33 \% ; p<0.05)$; however, embryo size was not significantly different between genders. Moreover, D15 female embryos had greater expression of G6PD $(p=0.05)$ and KRT8 $(p=0.03)$ than male embryos. In conclusion, the diluent used for tunnel construction affected embryo development in the post-hatching development (PHD) system, and the use of MQW was the most indicative measure for the evaluation of embryo quality. Male and female embryos cultured from D11 to D15, either in an MQW or PBS agarose gel, demonstrated similar development but different gene expression.
\end{abstract}

Keywords: Agarose gel, Cattle, Embryo culture, Gene expression, Sexing

\section{Introduction}

In spite of considerable progress achieved in the last few years in in vitro embryo production (IVP) technology in bovines, its overall efficiency is still modest, with blastocyst and pregnancy rates of roughly $40 \%$

\footnotetext{
${ }^{1}$ All correspondence to: Margot Alves Nunes Dode. Laboratory of Animal Reproduction, Embrapa Genetic Resources and Biotechnology, Parque Estação Biológica, PqEB, Av. W5 Norte (final), Caixa Postal 02372, Brasília, DF - Brazil 70.770-917. Tel. +55 61 34484659. Fax: +55 61 33403658. e-mail: margot@cenargen.embrapa.br.

${ }^{2}$ Laboratory of Animal Reproduction, Embrapa Genetic Resources and Biotechnology, Parque Estação Biológica PqEB - Av. W5 Norte (final), Caixa Postal 02372, Brasília, DF - Brazil - 70.770-917.

${ }^{3}$ College of Agriculture and Veterinary, University of Brasília, Campus Universitário Darcy Ribeiro - Asa Norte, Instituto Central de Ciências Ala Sul-Caixa Postal 4.508, Brasília, DF Brazil, CEP: 70.910-970.
}

(van Wagtendonk-de Leeuw, 2006; Schmidt, 2007; Lonergan \& Fair, 2008). A substantial number of studies have focused on improving embryo quality by analysing different variables that can influence the success of in vitro embryo development (Carolan et al., 1996; Fukui et al., 2000; Hendricksen et al., 2000; Khurana \& Niemann, 2000a; de Oliveira et al., 2005; Corrêa et al., 2008). The majority of those studies used, as an endpoint, blastocyst production on day (D)7 or D8 of the development or, more rarely, the pregnancy rate following embryo transfer to recipients. However, it is well known that blastocyst morphology is not highly indicative of an embryo's ability to initiate pregnancy following transfer. Unfortunately, the use of pregnancy rate as an endpoint is too expensive to be routinely used for embryo evaluation. Therefore, the development of new methods that are more reliable for the evaluation of the developmental potential of IVP embryos beyond the morphology at D7 and D8 would be very useful. 
Post-hatching in vitro culture of bovine embryos emerged as an alternative procedure that could potentially allow for the establishment of a more precise tool for evaluating embryo developmental ability, without the need of transferring them to recipients (Brandão et al., 2004; Vajta et al., 2004; Vejlsted et al., 2006). In this technique, it is possible to more accurately evaluate the quality of embryos produced by different assistedreproduction techniques (ARTs) as well as those submitted to different treatments and manipulations. Moreover, post-hatching development (PHD) systems could contribute to basic studies or to the investigation of toxicity of in vitro cultured products, pharmaceuticals, pesticides, and other chemicals (Brandão et al., 2004).

Although post-hatching in vitro culture of bovine embryos is an interesting system with a great potential to be used as a tool in studies involving ARTs, few studies have been done to better characterize, evaluate and optimize its use as an assessment parameter. Therefore, further studies are needed to determine basic characteristics such as the appropriate physical, chemical and hormonal environments required for embryo development to advanced stages in vitro. However, before a research investment is made to develop or establish new media and/or a different culture system, a better characterization of the one already established is needed to be used as a starting point.

One of the most important steps in the PHD system is the preparation of tunnels wherein the embryos are placed and then maintained during culture. The tunnels are prepared with agarose gel, which consists of compact bundles that form large pores allowing passage of solutes (Reece, 1996; Narayanan et al., 2006) in such a way that the cultured medium components can reach the embryo inside the tunnel. However, it is not known if changes, for example, in the diluents to prepare the tunnels, may affect the developmental abilities, kinetics of development and the molecular profile of embryos cultured in vitro for longer periods. Neither is it known if embryos of different gender will behave differently when cultured in such a system.

Thus, the objective of the present study was to evaluate the effect of the diluent used for tunnel preparation and gender on morphological characteristics, kinetics of development and gene expression of embryos cultured until D15 in a PHD system.

\section{Materials and methods}

\section{In vitro embryo production}

Unless otherwise indicated, chemicals were purchased from Sigma Chemical Co. Ovaries from crossbred cows (Bos taurus indicus $\times$ Bos taurus taurus) were collected immediately after slaughter and transported to the laboratory in saline solution $(\mathrm{NaCl} 0.9 \%)$ supplemented with penicillin $\mathrm{G}(100 \mathrm{UI} / \mathrm{ml})$ and streptomycin sulfate $(100 \mu \mathrm{g} / \mathrm{ml})$ at $35^{\circ} \mathrm{C}$. Cumulus-oocyte complexes (COCs) were aspirated from 2- to 8-mm diameter follicles with an 18-gauge needle and pooled in a $15-\mathrm{ml}$ conical tube. After sedimentation, COCs were recovered and selected using a stereomicroscope. Only COCs presenting homogenous cytoplasm and at least three layers of cumulus cells were used. Selected COCs were washed and transferred, in quantities of 30 to 35 , to a $200-\mu l$ drop of maturation medium under silicone oil and incubated for $22 \mathrm{~h}$ at $39^{\circ} \mathrm{C}$ and $5 \% \mathrm{CO}_{2}$ in air. Maturation medium consisted of TCM-199 (Invitrogen $\AA$ ) supplemented with $10 \%$ fetal bovine serum (FBS) (Invitrogen $\mathbb{R}$ ), $12 \mathrm{IU} / \mathrm{ml}$ of $\mathrm{LH}$, $0.01 \mathrm{IU} / \mathrm{ml}$ of $\mathrm{FSH}, 0.1 \mathrm{mg} / \mathrm{ml}$ of L-glutamine and antibiotic (Amicacin, $0.075 \mathrm{mg} / \mathrm{ml}$ ).

Following maturation, COCs were transferred to a 200- $\mu$ l drop of fertilization medium, which consisted of TALP (Parrish et al., 1995) supplemented with penicillamine $(2 \mathrm{mM})$, hypotaurine $(1 \mathrm{mM})$, epinephrine $(250 \mathrm{mM})$ and heparin $(10 \mu \mathrm{g} / \mathrm{ml})$. Frozen semen from a bull of known in vitro fertility, which has been used for several years as the reference bull for in vitro embryo production in our laboratory, was used for all treatments and replicates. Motile spermatozoa were obtained using the Percoll (Amersham Biosciences) gradient method in a microtube (Machado et al., 2009) and were added into the fertilization drop at a final concentration of $1 \times 10^{6}$ spermatozoa $/ \mathrm{ml}$. Sperm and oocytes were co-incubated for $20 \mathrm{~h}$ at $39^{\circ} \mathrm{C}$ with $5 \%$ $\mathrm{CO}_{2}$ in air, with the day of in vitro insemination considered as D0.

After co-incubation, the presumptive zygotes were washed and transferred to 200- $\mu$ l drops of SOFaaci medium (Holm et al., 1999) supplemented with 2.77 $\mathrm{mM}$ of myo-inositol and 5\% FBS and cultured at $39^{\circ} \mathrm{C}$ and $5 \% \mathrm{CO}_{2}$ in air for 7 days. Embryos were evaluated on $\mathrm{D} 2$ post-insemination (pi) for cleavage and on D6 and D7 pi for blastocyst rate.

\section{Post-hatching development (PHD) system}

The PHD system consisted of tunnels produced in agarose gel covered with culture medium as described by Brandão et al. (2004). These tunnels were made by dissolving low-melting-point agarose (Gibco BRL) in two different diluents at a final concentration of $2.4 \%$. In treatment 1 the agarose was diluted in PBS solution, and in treatment 2, it was diluted in MQW. In both treatments, $10 \%$ of FBS was added after the agarose was dissolved. Tunnels were prepared at least 1 day before use. Dishes with tunnels and PHD media (Brandão et al., 2004) were kept in an incubator at $39^{\circ} \mathrm{C}$ with $5 \% \mathrm{CO}_{2}$ in air until utilization. 
Table 1 Sequences of the primers used for sexing

\begin{tabular}{llcl}
\hline Primer & \multicolumn{1}{c}{ Primer sequence $5^{\prime} \rightarrow 3^{\prime}$} & Amplicon size (bp) & \multicolumn{1}{c}{ References } \\
\hline bSRY F & CCTCCCCTTCAAACGCCCGGAATCATT & 210 & Bondiolli et al. (1989) \\
bSRY R & GGCCATAGTCAGGATCTT & 280 & Ellis et al. (1988) \\
Autosomal F & CCCATCACCATCTTCCAGG & & \\
Autosomal R & AGTGAGCTTCCCGTTCAGC & & \\
\hline
\end{tabular}

F: forward; R: reverse; and size (bp) of the amplified fragments.

Embryos were evaluated on D8, and those with signs of degeneration were removed. On D9, only hatched blastocysts, without signs of degeneration, were kept in culture and $200 \mu \mathrm{l}$ of PHD medium was added to the droplets, increasing the final volume to $400 \mu \mathrm{l}$ (1:1 SOFaaci and SOFaaci PHD, respectively). On D11, embryos were evaluated under a stereomicroscope, and only those that presented a diameter $\geq 0.5 \mathrm{~mm}$, a clear trophoblast and a compact inner cell mass were transferred to agarose gel tunnels. At this time, embryos showing visible signs of degeneration were discarded. With the closed and bowled tip of a Pasteur pipette, each embryo was individually gently pushed inside the lumen of one gel tunnel. The loaded embryos remained in the PHD culture until D15. Culture was performed at $39^{\circ} \mathrm{C}$ and $5 \% \mathrm{CO}_{2}$ in air.

\section{Morphologic evaluation and kinetics of post-hatching embryo development}

Morphological and developmental evaluations of embryos were performed on D11, D12.5, D14 and D15 of culture. At each time point, embryos were measured using the Motic Images Plus 2.0 program. During the culture period, three patterns of development were observed: (1) embryos that reduced in size or showed signs of degeneration, which were classified as degenerated; (2) embryos that presented elongation and on D15 were reduced in size; and (3) embryos with continuous progressive daily elongation. On D15, only embryos that presented progressive elongation were removed from culture and frozen at $-80^{\circ} \mathrm{C}$ for gender diagnosis and gene expression.

\section{DNA, RNA extraction, and cDNA synthesis}

Elongated D15 embryos were used for individual extraction of genomic DNA and total RNA using Trizol Reagent (Invitrogen $\AA$ ). DNA was used for sex determination by PCR and RNA for gene expression evaluation via RT-qPCR.

In each microtube containing individual embryos, $50 \mu \mathrm{l}$ of Trizol (Invitrogen $\AA$ ) and $12.5 \mu \mathrm{g}$ of glycogen were added. Then, genomic DNA and total RNA were isolated according to the procedures provided by the manufacturer, with minor modifications. For gene expression, RNA of single embryos was pooled according to sex and size to form pools of three embryos in a total of three to four pools organized by sex.

Total RNA was incubated with 1 U DNase I (Invitrogen $R$ ) and then reverse transcribed with SuperScript III (200 U/ $\mu$ l; Invitrogen $®)$ and Oligo-dT primer (Invitrogen $($ ). Reactions were performed at $42^{\circ} \mathrm{C}$ for $52 \mathrm{~min}$ and at $70^{\circ} \mathrm{C}$ for $15 \mathrm{~min}$ for enzyme inactivation.

\section{Embryo sexing procedure}

Embryo sex determination was performed by PCR, using two pairs of primers. The first pair was specific to a region of the $Y$ chromosome, whereas the second pair was specific to a bovine autosomal gene. The primer sequences and fragment sizes for each gene are shown in Table 1. Bovine genomic DNA from a male and a female were used as a control. PCR was performed by adding to each sample tube a PCR mix containing $20 \mathrm{nM}$ of each pair of primers, $200 \mu \mathrm{M}$ of each dNTP, $1 \times$ PCR buffer and $1 \mathrm{U}$ Platinum Taq

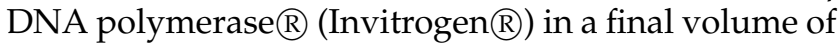
$30 \mu$ l. The PCR program used 40 cycles of $94{ }^{\circ} \mathrm{C}$ for $20 \mathrm{~s}, 57^{\circ} \mathrm{C}$ for $30 \mathrm{~s}$ and $72{ }^{\circ} \mathrm{C}$ for $30 \mathrm{~s}$, followed by a final extension of $72{ }^{\circ} \mathrm{C}$ for $30 \mathrm{~min}$. Amplified PCR products were electrophoresed in $2.0 \%$ agarose gel stained with ethidium bromide $(10 \mathrm{mg} / \mathrm{ml})$ and visualized under UV illumination. When two amplicons were detected, the embryo was identified as male, whereas detection of one amplicon indicated a female embryo.

\section{Real-time RT-PCR}

The relative abundance of genes involved in glucose metabolism [glucose-6-phosphate dehydrogenase $(G 6 P D)$, glucose transporter 1 (GLUT1), glucose transporter 3 (GLUT3), phosphoglycerate kinase 1 (PGK1)]; placenta development [placenta-specific 8 (PLAC8), keratin proteins 8 (KRT8)]; heat stress [heat shock transcription factors 1 (HSF1)]; and maternal recognition pregnancy [interferon- $\tau$ (IFNT)] compared between male and female embryos cultured in a PHD system using two different agar gel diluents.

Real-time RT-PCR analysis was performed using Power Sybr Green PCR Master Mix (Applied Biosystems). Reactions were performed in $25 \mu \mathrm{l}$, and PCR 
cycling conditions were $95^{\circ} \mathrm{C}$ for $10 \mathrm{~min}$ following by 40 cycles of denaturing at $95^{\circ} \mathrm{C}$ for $15 \mathrm{~s}$ and then annealing at the temperatures given in Table 2 for 1 min. Primer sequences, fragment size, annealing temperature and primer concentrations for each gene are listed in Table 2. Reactions were performed in duplicate for each gene, with an amplification efficiency of $>90 \%$.

To determine which housekeeping gene should be used for data normalization, the geNorm program was used (Vandesompele et al., 2002). Although the results indicated that cyclophilin-A (CYC-A) was the most stable endogenous control, rather than histone $\mathrm{H} 2 \mathrm{~A}(\mathrm{H} 2 \mathrm{~A})$ and glyceraldehyde-3-phosphate dehydrogenase $(G A P D H)$, the mean expression of these genes was used as endogenous control.

The relative abundance of each gene was calculated using the $\Delta \Delta C_{t}$ method with efficiency correction (Pfaffl, 2001). Mean efficiency values for each gene were calculated from the amplification profiles of individual samples using LinRegPCR software (Ramakers et al., 2003).

\section{Statistical analysis}

The percentage of elongated embryos in tunnels constructed using PBS solution and MQW and the proportion of elongated male and female embryos were evaluated by means of a chi-squared test. Data comparing embryos' lengths between D11 and D15 did not have normal distribution, even after logarithmic and square root transformations. At this point, they were analysed using the Mann-Whitney test. Gene expression data were analysed by means of a $t$-test or Mann-Whitney test for those with or without a normal distribution, respectively. All statistical analyses were performed using the Prophet Program, version 5.0; 1997.

\section{Results}

A total of 2933 oocytes were used for in vitro embryo production. Blastocyst rates were evaluated on D7 $(37 \% ; 1077 / 2933)$ and D8 $(41 \% ; 1216 / 2933)$ postinsemination (pi), the hatching rate was measured on D9 (72\%; 873/1216), and on D11, embryos were measured. Then, embryos presenting a diameter $\geq 0.5 \mathrm{~mm}(39.5 \% ; 345 / 873)$ were randomly distributed between two treatments for culture until D15. From the 345 D11 embryos with the minimum size necessary to continue their growth in vitro in the PHD system, 286 $(84 \%)$ were successfully loaded into the tunnels. Of those, $154(54 \%)$ and $132(46 \%)$ embryos were placed in tunnels made of agarose gel dissolved in MQW and PBS, respectively. The difference in the number of embryos available on D11 and those that were

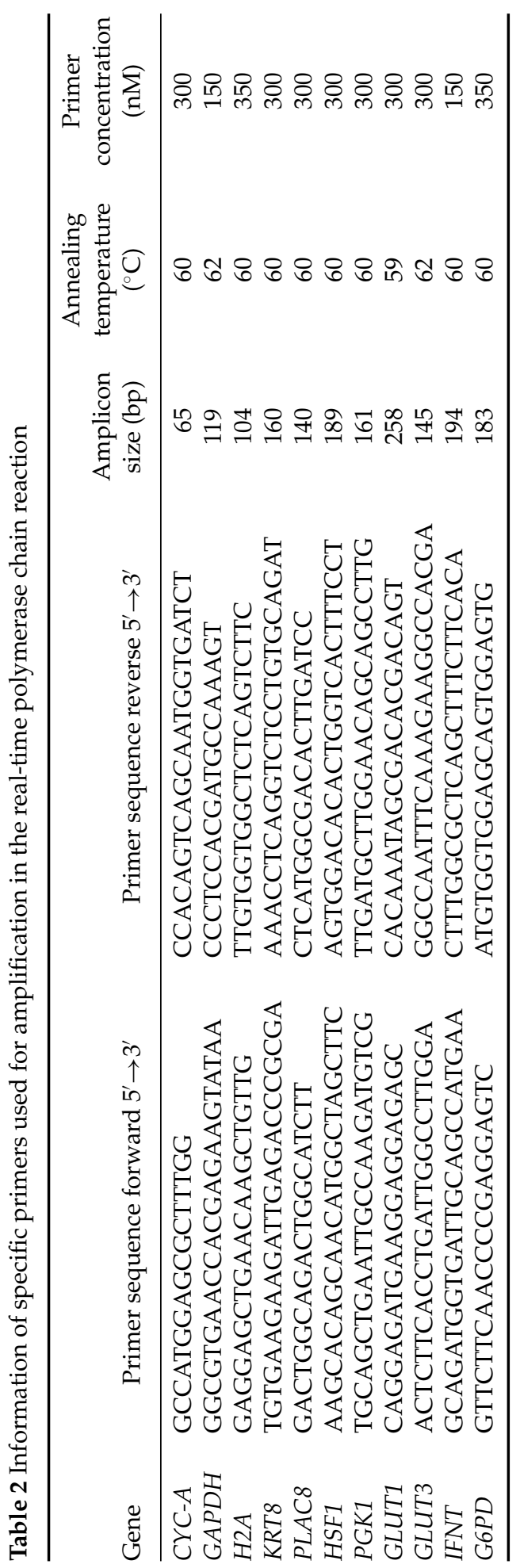




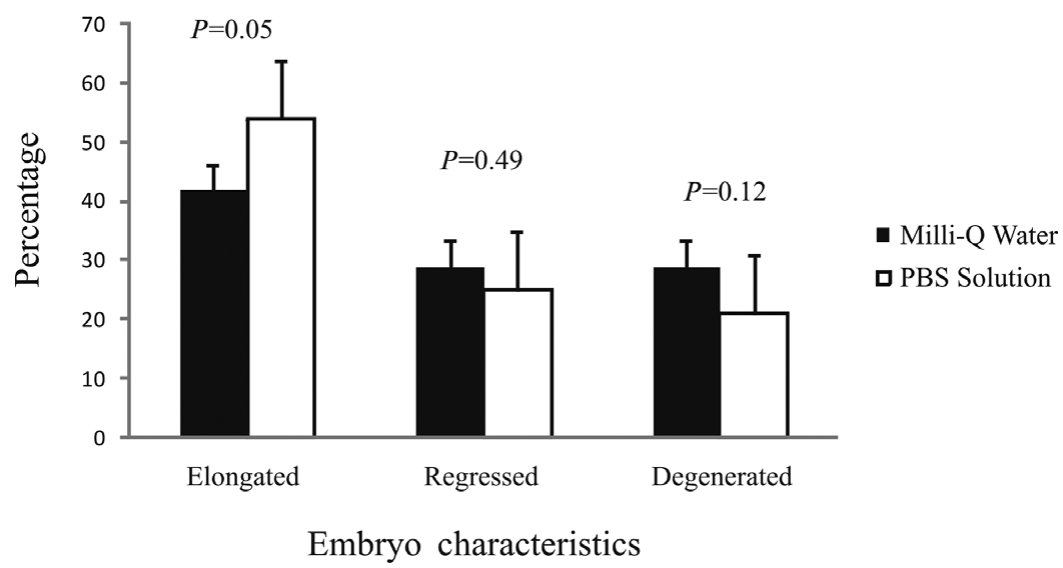

Figure 1 Percentage of embryos that elongate, regress and degenerate during culture in a post-hatching development (PHD) system from D11 to D15.

actually loaded into tunnels was due to morphological abnormalities of some embryos (unclear trophoblast and undefined inner cell mass), and the collapse of others when they were removed from the culture drop to be placed into the tunnels.

A general overview of embryo behaviour during culture in both PHD systems is shown in Fig. 1. The percentage of embryos elongated at D15 was higher in PBS than in MQW. Nevertheless, the percentages of embryos that grew, but regressed by D15, and those that degenerated were similar for the two types of gel.

Despite this, embryo development was higher in embryos cultured in MQW than in those cultured in PBS (Table 3). This finding can be observed not only by the size of the embryos on D15 but also by the total length increase during culture, which was calculated by subtracting the final (D15) length from the initial (D11) length for each embryo.

To evaluate whether or not the initial embryo size would affect development in the different PHD systems, we separated the embryos according to their size on D11 into two categories (Table 4). When development of embryos from the same size category was compared between two types of gels, we noted that smaller embryos had a similar pattern of development in both treatments. However, the bigger embryos demonstrated higher growth during the whole culture period when cultured in MQW as opposed to PBS.

Regarding gender evaluation, there was a higher proportion $(p<0.05)$ of male than female embryos on D15 of development in both PBS (67\% male, $n=39 / 58$ and $33 \%$ female, $n=19 / 58$ ) and MQW treatments (65\% male, $n=39 / 60$ and $35 \%$ female, $n=21 / 60)$. Although more male embryos developed in the PHD system, their morphology, final length and elongation pattern during culture was not affected by gender (Table 5). No differences were observed between the treatments when gender was considered.

To evaluate the effects of the diluents used for agarose gel on the quality of embryos using molecular profile as an endpoint, the relative expression of eight genes was analysed (Fig. 2). Only the GLUT1 gene showed a tendency $(p=0.08)$ to be expressed at a lower level in embryos cultured in MQW tunnels when compared with those cultured in PBS tunnels.

The expression of the same genes between male and female embryos was also compared independently of the treatments. In this analysis, the relative abundance of G6PD ( $p=0.05)$ and KRT8 ( $p=0.03)$ gene transcripts was higher in female than in male embryos on D15 (Fig. 3). The remaining genes showed no difference

Table 3 Average length (mm) of elongated bovine embryos (mean \pm SEM) on day (D)11, D12.5, D14 and D15 of cultured in a post-hatching development (PHD) system using agarose gel diluted in Milli-Q water or phosphate-buffered saline (PBS) solution

\begin{tabular}{|c|c|c|c|c|c|c|}
\hline \multirow[b]{2}{*}{ Agarose diluents } & \multirow[b]{2}{*}{$n$} & \multicolumn{5}{|c|}{ Average length of embryos (mm) } \\
\hline & & D 11 & D 12.5 & D 14 & D15 & $\mathrm{D} 15-\mathrm{D} 11^{a}$ \\
\hline PBS solution & 71 & $0.70 \pm 0.01$ & $0.90 \pm 0.03$ & $1.74 \pm 0.10$ & $2.37 \pm 0.13$ & $1.68 \pm 0.13$ \\
\hline Milli-Q water & 65 & $\begin{array}{c}0.70 \pm 0.02 \\
p=0.55\end{array}$ & $\begin{array}{c}1.05 \pm 0.05 \\
p=0.10\end{array}$ & $\begin{array}{c}2.53 \pm 0.23 \\
p=0.27\end{array}$ & $\begin{array}{c}3.03 \pm 0.23 \\
p=0.08\end{array}$ & $\begin{array}{c}2.33 \pm 0.22 \\
p=0.06\end{array}$ \\
\hline
\end{tabular}

${ }^{a}$ Difference between the final length of embryos on D15 and the initial length on D11. 
Table 4 Average length $(\mathrm{mm})$ of elongated bovine embryos (mean \pm SEM) of different size categories, on day (D)11, D12.5, D14 and D15 of cultured in a post-hatching development (PHD) system using agarose gel diluted in Milli-Q water or phosphate-buffered saline (PBS) solution

\begin{tabular}{|c|c|c|c|c|c|c|c|}
\hline \multirow[b]{2}{*}{ Agarose diluents } & \multirow[b]{2}{*}{$n$} & \multirow[b]{2}{*}{ Size category } & \multicolumn{5}{|c|}{ Average length of embryos (mm) } \\
\hline & & & D 11 & D 12.5 & D 14 & D15 & D15-D11 ${ }^{a}$ \\
\hline PBS solution & 33 & $0.5-0.69 \mathrm{~mm}$ & $0.59 \pm 0.01$ & $0.90 \pm 0.06$ & $1.71 \pm 0.12$ & $2.48 \pm 0.16$ & $1.89 \pm 0.16$ \\
\hline Milli-Q water & 35 & $0.5-0.69 \mathrm{~mm}$ & $\begin{array}{c}0.59 \pm 0.01 \\
p=0.91\end{array}$ & $\begin{array}{c}0.91 \pm 0.06 \\
p=0.96\end{array}$ & $\begin{array}{c}1.73 \pm 0.16 \\
p=0.36\end{array}$ & $\begin{array}{c}2.52 \pm 0.23 \\
p=0.56\end{array}$ & $\begin{array}{c}1.93 \pm 0.23 \\
p=0.55\end{array}$ \\
\hline PBS solution & 38 & $0.5-1 \mathrm{~mm}$ & $0.79 \pm 0.01$ & $0.90 \pm 0.03$ & $1.76 \pm 0.15$ & $2.29 \pm 0.21$ & $1.50 \pm 0.21$ \\
\hline Milli-Q water & 30 & $0.7-1 \mathrm{~mm}$ & $\begin{array}{c}0.82 \pm 0.23 \\
p=0.75\end{array}$ & $\begin{array}{c}1.22 \pm 0.08 \\
p=0.002\end{array}$ & $\begin{array}{c}2.53 \pm 0.23 \\
p=0.01\end{array}$ & $\begin{array}{c}3.62 \pm 0.39 \\
p=0.001\end{array}$ & $\begin{array}{c}2.80 \pm 0.38 \\
p=0.001\end{array}$ \\
\hline
\end{tabular}

${ }^{a}$ Subtraction of the final length of embryos on D15 and the initial length on D11.

Table 5 Average length (mm) of male and female bovine embryos (mean \pm SEM) cultured in a post-hatching development (PHD) system using agarose gel diluted in Milli-Q water or phosphate-buffered saline (PBS) solution on day (D)11, D12.5, D14 and D15 of culture

\begin{tabular}{llccccc}
\hline & & \multicolumn{5}{c}{ Average length of embryos (mm) } \\
\cline { 3 - 6 } Agarose diluents & \multirow{2}{*}{ Gender } & D 11 & D 12.5 & D 14 & D15 & D15-D11 $^{a}$ \\
\cline { 3 - 6 } PBS solution & Male (39/58) & $0.69 \pm 0.02$ & $0.92 \pm 0.05$ & $1.74 \pm 0.15$ & $2.42 \pm 0.21$ & $1.73 \pm 0.20$ \\
PBS solution & Female (19/58) & $0.67 \pm 0.04$ & $0.83 \pm 0.04$ & $1.45 \pm 0.15$ & $1.99 \pm 0.17$ & $1.33 \pm 0.16$ \\
& & $p=0.80$ & $p=0.61$ & $p=0.26$ & $p=0.39$ & $p=0.46$ \\
Milli-Q water & Male (39/60) & $0.70 \pm 0.03$ & $1.02 \pm 0.07$ & $2.00 \pm 0.19$ & $2.95 \pm 0.31$ & $2.24 \pm 0.29$ \\
Milli-Q water & Female (21/60) & $0.67 \pm 0.03$ & $0.97 \pm 0.09$ & $1.92 \pm 0.25$ & $2.75 \pm 0.37$ & $2.08 \pm 0.36$ \\
& & $p=0.56$ & $p=0.49$ & $p=0.66$ & $p=0.73$ & $p=0.76$ \\
\hline
\end{tabular}

${ }^{a}$ Subtraction of the final length of embryos on D15 and the initial length on D11.

in expression between genders. Also, no effect of the interaction between diluents and gender was observed in the gene expression of embryos.

\section{Discussion}

In this study, we evaluated the development and gene expression of male and female embryos cultured up to D15 in a PHD system using PBS and MQW tunnels. Our findings demonstrated that tunnel diluents, but not gender, affected embryo development, in which embryo growth in the different tunnels was dependent on the initial embryo size. Additionally, despite the fact that female and male embryos had similar developmental kinetics, they differed in gene expression.

Regarding embryo development, we noted that the overall percentage of embryos that elongated until D15 was higher than that reported by Brandão et al. (2004). In addition, the mean length of embryos cultured in tunnels prepared either with PBS or MQW was comparable with the length of IVP embryos, which were transferred on D7 to a synchronized recipient and recovered on D12 (Lazzari et al.,
2002) and on D14 (Fischer-Brown et al., 2004). These results suggest that the system we used was suitable to provide growth and elongation of IVP embryos.

Even though more than $40 \%$ of the embryos that were loaded in the tunnels on D11 showed continuous growth and were elongated on D15, only $32 \%$ of D7 blastocysts were able to reach the minimum size with the morphological normality required to continue PDH culture. A high rate of embryonic loss from D8 to D11 was also reported by Brandão et al. (2004). These results suggested that this period of time is critical for the embryo. Indeed, it has been reported that post-hatching embryos may be very susceptible to environmental stress as a result of increased metabolism, protein synthesis and energy demand (Tiffin et al., 1991; Khurana \& Niemann, 2000b; Garner, 2008).

The percentage of embryos that grew was higher in the PBS tunnel than in the MQW tunnel; however, the increase in size during development was more pronounced in embryos cultured in MQW gel. Therefore, this gel appeared to give a better indication of embryo quality, as it permitted a greater increase in size than the PBS gel. This assumption is based on other studies, which have reported that morphological 

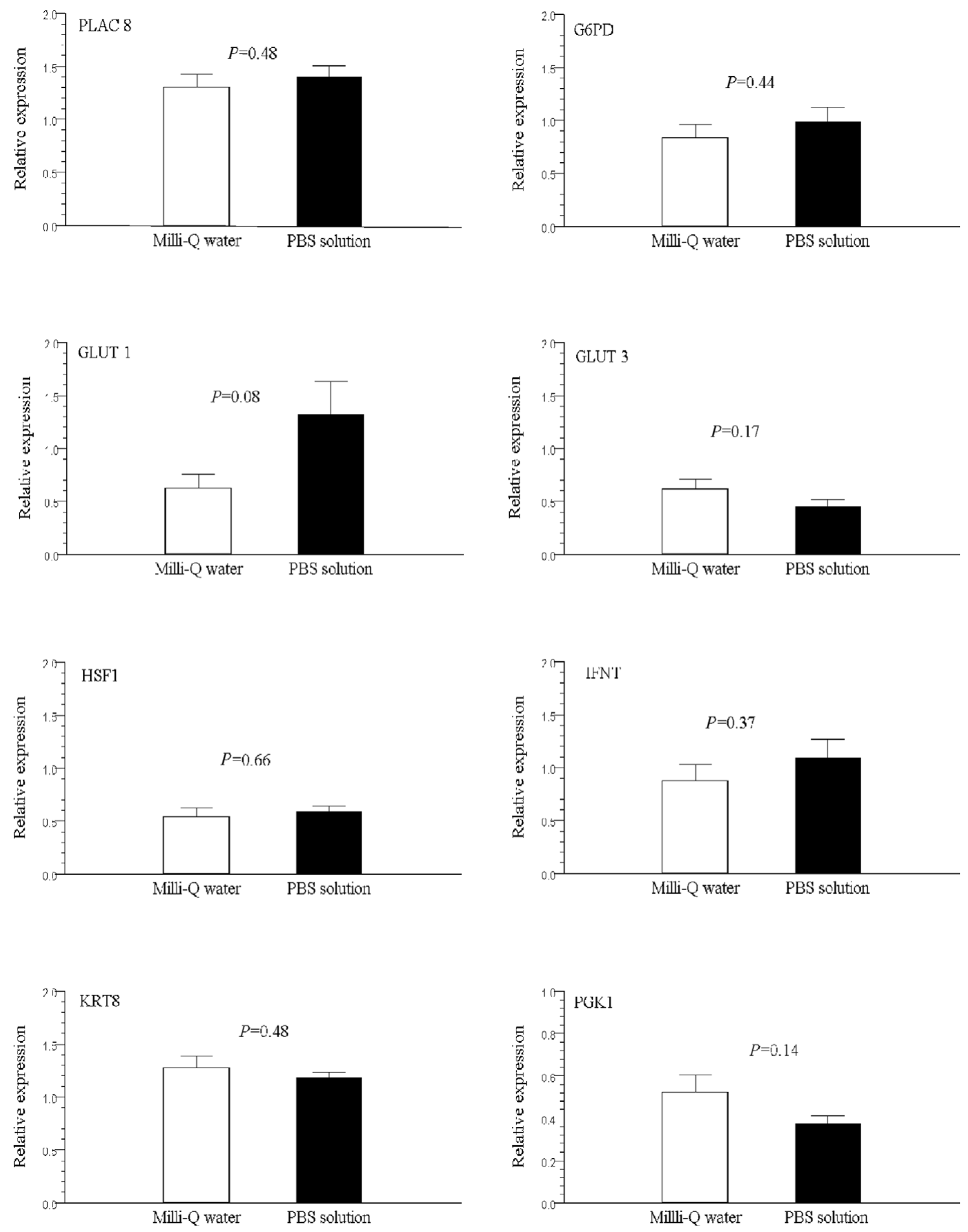

Figure 2 Transcript levels of PLAC8, G6PD, GLUT1, GLUT3, HSF1, IFNT, KRT8 and PGK1 genes as determined by real-time polymerase chain reaction in day (D)15 bovine embryos culture in post-hatching system using agarose gel tunnels diluted in Milli-Q water and phosphate-buffered saline (PBS) solution. Data are mean \pm SEM. Data were normalized against the mean of $C Y C-A, G A P D H$ and $H 2 A$ genes, with results expressed relative to the control sample using the $\Delta \Delta C_{t}$ method with efficiency correction.

characteristics on D14 may be a good indicator of embryo fitness, as these characteristics were associated with pregnancy establishment (Fisher-Brown et al., 2004). In addition, the length of D14 embryos has been positively correlated with IFNT secretion (Block et al., 2007), suggesting that the more highly developed embryos are better able to prevent initial luteal regression and to maintain pregnancy. 

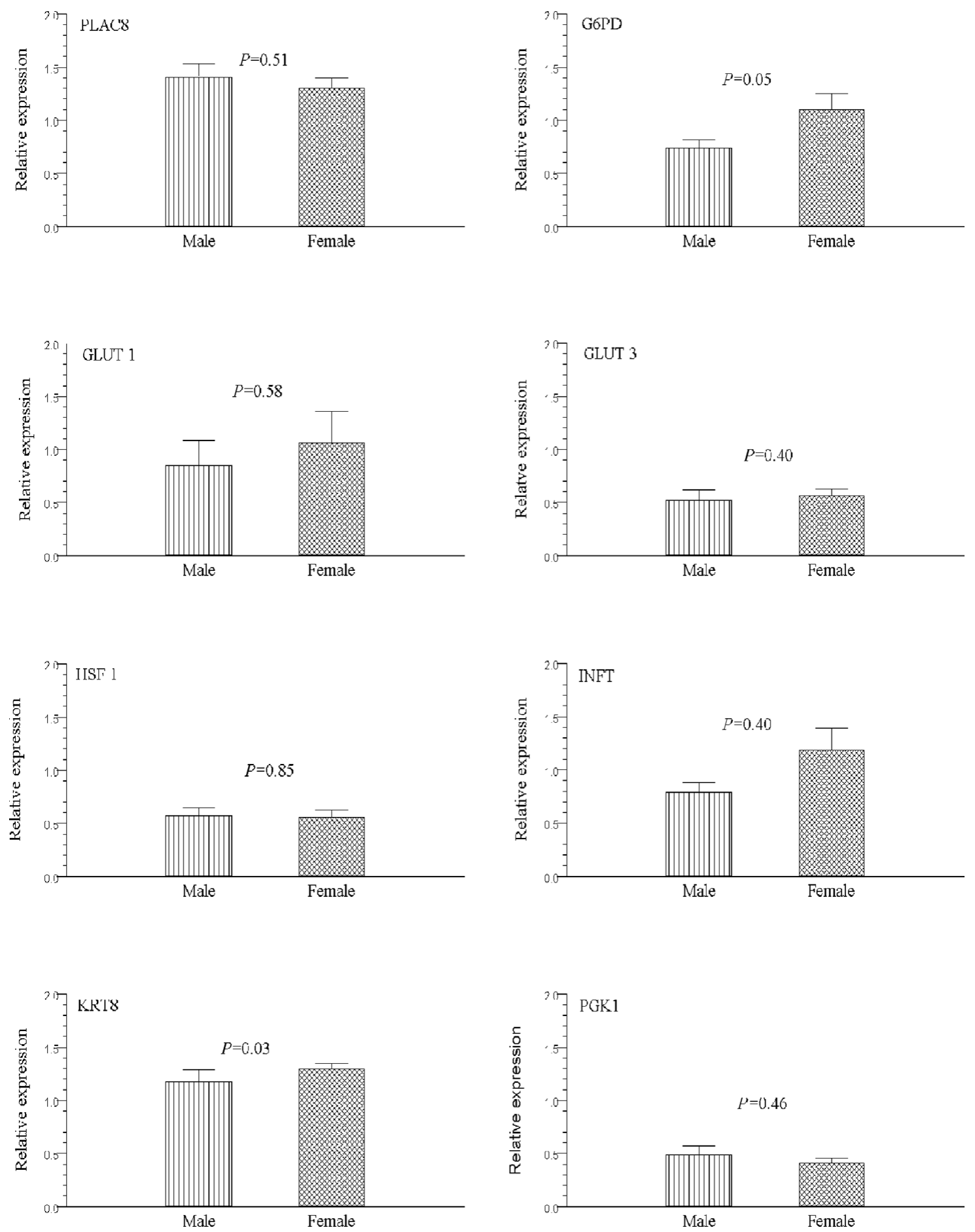

Figure 3 Transcript levels of PLAC8, G6PD, GLUT1, GLUT3, HSF1, IFNT, KRT8 and PGK1 genes as determined by polymerase chain reaction in day (D)15 male and female bovine embryos culture in post-hatching system using agarose gel tunnels. Data are mean \pm SEM. Data were normalized against the mean of $C Y C-A, G A P D H$ and $H 2 A$ genes, with results expressed relative to the control sample using the ${ }^{\Delta \Delta} \mathrm{C}_{\mathrm{t}}$ method.

Because Brandão et al. (2004) had determined that the size of the embryo on D11 could be used to qualify and to estimate the subsequent development, we investigated whether or not the initial size of the embryo on D11 would affect its growth in the PHD system using different agarose diluents. Therefore, we separated embryos into two categories according to their size. It was observed that the final embryo size and the elongation pattern were similar for both types of gels for smaller embryos. However, larger 
embryos had a higher developmental rate during the entire culture period in MQW gel. Considering that the elongating stage is an indicator of embryo viability, as stated by Fischer-Brown et al. (2004), and has been used as an indicator of embryo quality (Clemente et al., 2009), we can hypothesise that MQW gel may provide a better indication of those embryos with higher developmental potential.

Aside from testing tunnel gel composition, we focused on the comparison of the morphological characteristics and the kinetics of development of male and female embryos. Gender determination on D15 demonstrated a significant sex ratio shift, in which the majority of the embryos were male. A much more notable imbalance in favour of male embryos on D16 using a PHD system was observed by Brandão et al. (2004). Conversely, when IVP embryos were maintained in the recipient uterus from D7 to D16, a tendency of IVP embryos to have more males than females was observed (Bertolini et al., 2002). The difference in the sex ratio of IVP embryos has been attributed to several factors, including glucose concentration in the culture medium (Gutiérrez-Adán et al., 2001), which could explain the lower percentage of female embryos on D15 that we observed. Interestingly, we also sexed the embryos that were removed from culture on D9 because they had not hatched, and found that of the discarded embryos, $60 \%$ were females (data not shown). Because PHD medium, which contained a high concentration of glucose, was only added to the culture on D9, we might assume that the lesser development of females was not due to the presence of a high glucose concentration. It is possible that a greater female sensitivity to the culture environment may be due to the process of $X$ chromosome inactivation, which should occur before the embryos were placed in the PHD system, as stated by others (Latham, 1996; Gutiérrez-Adán et al., 2001; Okamoto et al., 2004; Ferreira et al., 2010). In addition, it is very likely that the difference in the sex ratio observed on D15 was already present on D11 when embryos were placed in the agarose tunnels.

Although a lower percentage of female embryos reached the size required to be placed in the tunnels, those that were loaded showed similar size and a similar pattern of development to that of male embryos. Because the period of greatest embryonic loss is between D7 and D11 and females are more susceptible to culture environment, those that survived and reached D11 had most likely gone through a robust selection process and were similar in quality to male embryos.

Gene expression has been widely used to evaluate embryo quality (Rizos et al., 2002; Gutiérrez-Adán et al., 2004; Lonergan et al., 2006). Therefore, we also used this approach to examine the suitability of the utilized PHD system and to evaluate gender differences. The significance of the genes we chose resides in their close association with placenta development, heat stress, maternal recognition of pregnancy and glucose metabolism.

When comparing agarose gels treatments, only the transcript levels of the GLUT1 gene had a tendency $(p=0.08)$ to be more abundant in the elongated D15 embryos cultured in PBS gel. Different groups have studied gene expression patterns of glucose transporters during the preimplantation period in bovines, but the results were variable when in vivo and in vitro embryos were compared (Lazzari et al., 2002; Harvey et al., 2004; Balasubramanian et al., 2007). In the present study, GLUT1, but not GLUT3, had a tendency to be more highly expressed in PBS gel. This differential expression suggests that diluents may affect glucose uptake and embryo metabolism, but the reason for this is not clear. It is important to highlight the fact that GLUT1 has a role in intercellular, rather than apical, transport of glucose, meaning that its expression does not necessarily imply a dominant role in embryonic uptake from the environment, as it does with GLUT3 (Augustin et al., 2001).

There is a general understanding that male IVP embryos develop faster than female embryos, which has been attributed to higher glucose uptake and metabolism (Gutiérrez-Adán et al., 2001; Rheingantz et al., 2004; Morton et al., 2007). In the present study, we were not able to find a difference in the expression of glucose transport genes (GLUT1 and GLUT3) between male and females embryos. Bertolini et al. (2002) found that D16 male embryos expressed more transcripts for GLUT1 and GLUT3 than did female embryos. However, they also demonstrated that expression of those genes was correlated with embryo development, as evaluated by physical length. These observations could explain our results, as D15 male and female embryos had similar development rates and lengths.

Even though glucose transport and uptake are part of the complex metabolism of glucose, there are other factors involved that can differ according to gender, such as $\mathrm{X}$ chromosome-linked enzymes (Tiffin et al., 1991; De La Fuente et al., 1999). G6PD and PGK1 are some of the enzymes related to energetic metabolism that are linked to the $X$ chromosome. In the present study, a higher expression of the G6PD gene was detected in D15 female embryos than in male embryos. Results of several experiments demonstrated that female in vitro embryos on D7 presented a greater expression of G6PD than did male embryos (De La Fuente et al., 1999; Gutierrez-Adán et al., 2000). Hence, it could be speculated that an in vitro culture environment may somehow affect the $\mathrm{X}$-inactivation process by modifying the pattern of G6PD gene 
expression (Lonergan et al., 2003; Balasubramanian et al., 2007; Morton et al., 2007). However, considering the importance of that process for female embryo survival, we believe that if any alteration had occurred, the female embryos would not be able to develop until D15 and instead would halt their development at earlier stages. In addition, no changes were observed in the PGK1 gene, which is also an X-linked gene. Therefore, we can hypothesise that the increase in the expression of the G6PD gene, as observed here, may be more highly associated with higher viability, in response to adverse conditions, than to problems in the $X$ chromosome inactivation.

This hypothesis is supported by the greater expression, in D15 female embryos, of the KRT8 gene, which is involved in placentation and subsequent implantation, than that in male embryos. The KRT8 protein is critical for post-hatching development of bovine embryos (Maddox-Hyttel et al., 2003) and its deficiency has been associated with embryonic death in mice (Jaquemar et al., 2003). Lower expression of this gene has been reported in nuclear transfer (NT) embryos when compared with IVF (Pfister-Genskow et al., 2005).

In conclusion, we noted that agarose diluent used for tunnel construction affects embryo development in the PHD system and that the use of MQW was most indicative of the ability to evaluate embryo quality. Furthermore, it is important to highlight that although fewer female embryos developed to D11, those that survived this critical phase and were submitted to the PHD system had a similar morphology and elongation pattern to that seen in male embryos. Also, the differences we found in the expression of some genes evaluated were more strongly related to gender than to embryo quality. Therefore, embryo development in the PHD system is not influenced by gender and can be used to compare D15 embryos.

\section{Acknowledgements}

G. M. Machado received a scholarship from CAPESBrazil. This research was supported by Embrapa (Grant no. 003.0709040000) and CNPq (Grant no. 475412/2007-9), Brazil. The authors thank the Laboratory of Ovarian Molecular Physiology, UNESPBotucatu, São Paulo, Brazil, for assistance in the gene expression analysis of bovine embryos.

\section{References}

Augustin, R., Pocar, P., Navarrete-Santos, A., Wrenzycki, C., Gandolfi, F., Niemann, H. \& Fischer, B. (2001). Glucose transporter expression is developmentally regulated in in vitro derived bovine preimplantation embryos. Mol. Reprod. Dev. 60, 370-6.
Balasubramanian, S., Son, W.J., Mohana Kumar, B., Ock, S.A., Yoo, J.G., Im, G.S., Choe, S.Y. \& Rho, G.J. (2007). Expression pattern of oxygen and stress-responsive gene transcripts at various developmental stages of in vitro and in vivo preimplantation bovine embryos. Theriogenology 68 , 265-75.

Bertolini, M., Beam, S.W., Shim, H., Bertolini, L.R., Moyer, A.L., Famula, T.R. \& Anderson, G.B. (2002). Growth, development, and gene expression by in vivo- and in vitroproduced day 7 and 16 bovine embryos. Mol. Reprod. Dev. 63, 318-28.

Block, J., Fischer-Brown, A.E., Rodina, T.M., Ealy, A.D. \& Hansen, P.J. (2007). The effect of in vitro treatment of bovine embryos with IGF-1 on subsequent development in utero to day 14 of gestation. Theriogenology 68, 153-61.

Bondiolli, K.R., Ellis, S.B., Pryor, J.H., Williams, M.W. \& Harpold, M.M. (1989). The use of male-specific chromosomal DNA fragments to determine the sex of bovine preimplantation embryos. Theriogenology 41, 95104.

Brandão, D.O., Hyttel, P., Lovendahl, P., Rumpf, R., Stringfellow, D. \& Callesen, H. (2004). Post-hatching development: a novel system for extended in vitro culture of bovine embryos. Biol. Reprod. 71, 2048-55.

Carolan, C., Lonergan, P.K. \& Mermillod, P. (1996). In vitro production of bovine embryos using individual oocytes. Mol. Reprod. Dev. 45, 145-50.

Clemente, M., de la Fuente, J., Fair, T., Al Naib, A., Gutierrez-Adan, A., Roche, J.F., Rizos, D. \& Lonergan. (2009). Progesterone and conceptus elongation in cattle: a direct effect on the embryo or an indirect effect via the endometrium? Reproduction 138, 507-17.

Corrêa, G.A., Rumpf, R., Mundim, T.C., Franco, M.M. \& Dode, M.A. (2008). Oxygen tension during in vitro culture of bovine embryos: effect in production and expression of genes related to oxidative stress. Anim. Reprod. Sci. 104, 132-42.

De La Fuente, R., Hahnel, A., Basrur, P.K. \& King, W.A. (1999). X inactive-specific transcript (Xist) expression and $X$ chromosome inactivation in the preattachment bovine embryo. Biol. Reprod. 60, 769-75.

de Oliveira, A.T., Lopes, R.F. \& Rodrigues, J.L. (2005). Gene expression and developmental competence of bovine embryos produced in vitro under varying embryo density conditions. Theriogenology 64, 1559-72.

Ellis, S.B., Bondiolli, K.W. \& Williams, M.E. (1988). Sex determination of bovine embryos using male-specific DNA probes. Theriogenology 29, 242.

Ferreira, A.R., Machado, G.M., Diesel, T.O., Carvalho, J. O., Rumpf, R., Melo, E.O., Dode, M.A.N. \& Franco, M.M. (2010). Allele-specific expression of the MAOA gene and $\mathrm{X}$ chromosome inactivation in in vitro produced bovine embryo. Mol. Reprod. Dev. 77, 615-21.

Fischer-Brown, A.E., Lindsey, B.R., Ireland, F.A., Northey, D.L., Monson, R.L., Clark, S.G., Wheeler, M.B., Kesler, D.J., Lane, S.J., Weigel, K.A. \& Rutledge, J.J. (2004). Embryonic disc development and subsequent viability of cattle embryos following culture in two media under two oxygen concentrations. Reprod. Fert. Dev. 16, 787-93.

Fukui, Y., Kikuchi, Y., Kondo, H. \& Mizushima, S. (2000). Fertilizability and developmental capacity of individuality culture bovine oocytes. Theriogenology 53, 1553-65. 
Garner, D.K. (2008). Dissection of culture media for embryos: the most important and less important components and characteristic. Reprod. Fert. Dev. 20, 9-18.

Gutiérrez-Adán, A., Oter, M., Martínez-Madrid, B., Pintado, B. \& De La Fuente, J. (2000). Differential expression of two genes located on the $\mathrm{X}$ chromosome between male and female in vitro-produced bovine embryos at the blastocyst stage. Mol. Reprod. Dev. 55, 146-51.

Gutiérrez-Adán, A., Lonergan, P., Rizos, D., Ward, F.A., Boland, M.P., Pintado, B. \& De La Fuente, J. (2001). Effect of the in vitro culture system on the kinetics of blastocyst development and sex ratio of bovine embryos. Theriogenology 55, 1117-25.

Gutiérrez-Adán, A., Rizos, D., Fair, T., Moreira, P.N., Pintado, B., De La Fuente, J., Boland, M.P. \& Lonergan, P. (2004). Effect of speed of development on mRNA expression pattern in early bovine embryos cultured in vivo or in vitro. Mol. Reprod. Dev. 68, 441-8.

Harvey, A.J, Kind, K.L., Pantaleon, M., Armstrong, D.T. \& Thompson, J.G. (2004). Oxygen-regulated gene expression in bovine blastocysts. Biol. Reprod. 71, 1108-19.

Hendricksen, P.J., Vos, P.L., Steenweg, W.N., Bevers, M.M. \& Dieleman, S.J. (2000). Bovine follicular development and its effect on the in vitro competence of oocytes. Theriogenology 53, 11-20.

Holm, P., Booth, P.J., Schimidt, M.H., Greve, T. \& Callesen, H. (1999). High bovine blastocyst development in a static in vitro production system using SOFaa medium supplemented with sodium citrate and myo-inositol with or without serum proteins. Theriogenology 52, 683-700.

Jaquemar, D., Kupriyanov, S., Wankell, M., Avis, J., Benirschke, K., Baribault, H. \& Oshima, R.G. (2003). Keratin 8 protection of placental barrier function. J. Cell Biol. 161, 749-56.

Khurana, N.K. \& Niemann, H. (2000a). Effects of oocyte quality, oxygen tension, embryo density, cumulus cells and energy substrates on cleavage and morula/blastocyst formation of bovine embryos. Theriogenology 54, 741-56.

Khurana, N.K. \& Niemann, H. (2000b). Energy metabolism in preimplantation bovine embryos derived in vitro or in vivo. Biol. Reprod. 62, 847-56.

Latham, K.E. (1996). X chromosome imprinting and inactivation in the early mammalian embryo. Trends Genet. 12, 134-7.

Lazzari, G., Wrenzycki, C., Herrman, D., Duchi, R., Kruip, T., Niemann, H. \& Galli, C. (2002). Cellular and molecular deviations in bovine in vitro-produced are related to the large offspring syndrome. Biol. Reprod. 67, 767-75.

Lonergan, P \& Fair, T. (2008). In vitro-produced bovine embryos-dealing with the warts. Theriogenology 69, $17-22$.

Lonergan, P., Rizos, D., Gutiérrez-Adán, A., Moreira, P.M., Pintado, B., De La Fuente, J. \& Boland, M.P. (2003). Temporal divergence in the pattern of messenger RNA expression in bovine embryos cultured from the zygote to blastocyst stage in vitro or in vivo. Biol. Reprod. 69, 1424-31.

Lonergan, P., Fair, T., Corcoran, D. \& Evans, A.C.O. (2006). Effect of culture environment on gene expression and developmental characteristic in IVF-derived embryos. Theriogenology 65, 137-52.
Machado, G.M., Carvalho, J.O., Siqueira Filho, E., Caixeta, E.S., Franco, M.M., Rumpf, R. \& Dode, M.A.N. (2009). Effect of Percoll volume, duration and force of centrifugation, on in vitro production and sex ratio of bovine embryos. Theriogenology 71, 1289-97.

Maddox-Hyttel, P., Alexopoulos, N.I., Vajta, G., Lewis, I., Rogers, P., Cann, L., Callesen, H., Tveden-Nyborg, P. \& Trounson, A. (2003). Immunohistochemical and ultrastructural characterization of the initial post-hatching development of bovine embryos. Reproduction 125, 607-23.

Morton, K.M., Herrmann, D., Sieg, B., Struckmann, C., Maxwell, W.M.C., Raht, D., Evans, G., Lucas-Hahn, A., Niemann, H. \& Wrenzycki, C. (2007). Altered mRNA expression patterns in bovine blastocysts after fertilization in vitro using flow-cytometrically sex-sorted sperm. Mol. Reprod. Dev. 74, 931-40.

Narayanan, J., Xiong, J.Y. \& Liu, X.Y. Determination of agarose gel pore size: absorbance measurements vis à vis other techniques. (2006). J. Phys. Conf. Ser. 28, 83-6.

Okamoto, I., Otte, A.P., David Allis, C., Reinberg, D. \& Heard, E. (2004). Epigenetic dynamics of imprinted $X$ inactivation during early mouse development. Science 303, 644-9.

Parrish, J.J., Krogenaes, A. \& Susko-Parrish, J.L. (1995). Effect of bovine sperm separation by either swim-up and Percoll method on success of in vitro fertilization and early embryonic development. Theriogenology 44, 859-69.

Pfaffl, M.W. (2001). A new mathematical model for relative quantification in real-time RT-PCR. Nucl. Acids Res. 29, 2002-7.

Pfister-Genskow, M., Myers, C., Childs, L.A., Lacson, J.C., Patterson, T., Betthauser, J.M., Goueleke, P.J., Koppang, R.W., Lange, G., Fisher, P, Watt, S.R., Forsberg, E.J., Zheng, Y., Leno, G.H., Schultz, R.M., Liu, B., Chetia, C., Yang, X. \& Hoeschele, I., Eilertsen, K.J. (2005). Identification of differentially expressed genes in individually bovine preimplantation embryos produced by nuclear transfer: improper reprogramming of genes required for development. Biol. Reprod. 71, 546-55.

Ramakers, C., Ruijter, J.M., Deprez, R.H. \& Moorman, A.F. (2003). Assumption-free analysis of quantitative real-time polymerase chain reaction (PCR) data. Neurosci. Lett. 339, 62-6.

Reece, W.O. (1996). Fisiologia dos Animais Domésticos, In Propriedades físico-químicas das soluções (eds Swenson M.J. \& Reece W.O.), pp. 1-7. Rio de Janeiro, Brazil: Guanabara Koogan S.A.

Rheingantz, M.G.T., Pegoraro, L.M.C., Dellagostin, O.A., Pimentel, A.M., Bernardi, M.L. \& Deschamps, J.C. (2004). Proporção macho: fêmea de embriões bovinos cultivados na presença ou ausência de glicose após FIV com espermatozóides selecionados por swim-up ou Gradiente de Percoll. Braz. J. Vet. Res. Anim. Sci. 41, 32-9.

Rizos, D., Lonergan, P., Boland, M. P., Arroyo-Gárcia, R., Pintado, B., Fuente, J. \& Gutiérrez-Adán, A. (2002). Analysis of differential messenger RNA expression between bovine blastocysts produced in different culture system: implications for blastocysts quality. Biol. Reprod. 66, 589-95.

Schmidt, M. (2007). Perinatal death associated with ET, IVP, and cloning in cattle. Acta Vet. Scand. 49, S13. 
Tiffin, G.J., Rieger, D., Betteridge, K.J., Yadav, B.R. \& King, W.A. (1991). Glucose and glutamine metabolism in preattachment cattle embryos in relation to sex and stage of development. J. Reprod. Fertil. 93, 125-32.

Vajta, G., Alexopoulus, N. \& Callesen, H. (2004). Rapid growth and elongation of bovine blastocysts in vitro in a three-dimensional gel system. Theriogenology 7, 1253-63.

van Wagtendonk-de Leeuw, A.M. (2006). Ovum pick up and in vitro production in the bovine after use in several generations: a 2005 status. Theriogenology 65, 914-25.
Vandesompele, J., Preter, K.D., Pattyn, F., Poppe, B., Roy, N.V., Paepe, A.D. \& Speleman, F. (2002). Accurate normalization of real-time quantitative RT-PCR data by geometric averaging of multiple internal control genes. Gen. Biol. 3, 1-11.

Vejlsted, M., Du, Y., Vajta, G. \& Maddox-Hytttel, P. (2006). Post-hatching development of porcine and bovine embryo - defining criteria for expected development in vivo and in vitro. Theriogenology 65, 1536. 